\title{
Intravenous gammaglobulins in refractory polymyositis: lower dose for maintenance treatment is effective
}

\author{
S Genevay, A Saudan-Kister, P-A Guerne
}

\begin{abstract}
Objectives-To test lower dose immunoglobulins as a maintenance treatment in a patient with refractory polymyositis.

Methods-In a patient with longstanding refractory polymyositis, intravenous (IV) immunoglobulin treatment was introduced at a standard dose ( $2 \mathrm{~g} / \mathrm{kg}$ monthly). After a few treatment courses, doses were reduced to $0.8 \mathrm{~g} / \mathrm{kg}$ monthly, allowing perfusion over one single day.

Results-Although response to the standard dose was only partial, reduction of subsequent doses did not alter the evolution. On the contrary, the evolution was marked by further improvement, which has been sustained over the following year. Conclusion-Lower dose IV immunoglobulins as a maintenance treatment were used with excellent results in a case of refractory polymyositis allowing considerable reduction in treatment costs. Further trials should be undertaken to evaluate this interesting alternative.

(Ann Rheum Dis 2001;60:635-636)
\end{abstract}

Polymyositis (PM), whose cause remains unknown, is generally treated with corticosteroids as a first line treatment, with the addition, when there is resistance or side effects, of immunosuppressive agents (azathioprine, methotrexate, cyclosporin, or cyclophosphamide), which have also potentially serious toxicity. The efficacy of high dose intravenous (IV) immunoglobulins has been documented for several autoimmune diseases, including inflammatory myopathies. Dermatomyositis (DM) is the only inflammatory myopathy for which a controlled trial has shown a clear cut effect. ${ }^{1}$ In $\mathrm{PM}$, only case-control or mixed PM/DM open label studies have been reported, ${ }^{2}{ }^{3}$ and record lower and less consistent efficacy. The dose of 2 $\mathrm{g} / \mathrm{kg}$ is generally given over two or five days. We describe a dramatic response to IV immunoglobulins in a patient who previously developed side effects or was resistant to three different immunosuppressive agents. During a year of treatment, it appeared that lower maintenance doses, given over a shorter period of time, were at least as effective as more classical regimens.

\section{Case report}

A 53 year old man was referred to our clinic at the end of 1992, complaining of several months of symmetrical weakness and muscle pains in his legs. Serum creatine kinase (CK) was raised at $2555 \mathrm{U} / 1$; the erythrocyte sedimentation rate, $\mathrm{C}$ reactive protein, and liver enzymes were normal. Antinuclear antibodies and anti-Jo-1 were negative. Electromyography of the quadriceps femoralis showed alterations typically consistent with myositis and the biopsy demonstrated interstitial inflammatory infiltrates (lymphocytes and macrophages), together with fibre alterations with necrosis and regeneration. PM was diagnosed and prednisone started at $1 \mathrm{mg} / \mathrm{kg}$ (90 mg/day), with complete clinical and biological response within a few weeks.

Failure to taper prednisone to under 30 $\mathrm{mg} /$ day led us to first introduce azathioprine (AZA) at $200 \mathrm{mg} /$ day in April 1993, then replaced by methotrexate (MTX) at $15 \mathrm{mg}$ / week in summer 1993, and later increased to $25 \mathrm{mg} /$ week. Because of persistent disease resistance (CK $3035 \mathrm{U} / \mathrm{l}$ ), and increased liver enzymes (serum aspartate transaminase (AST) and serum alanine transaminase (ALT)), cyclosporin (CSA) $(200 \mathrm{mg} /$ day) was added in autumn 1994, later increased to $300 \mathrm{mg} /$ day, and MTX reduced to $20 \mathrm{mg} /$ week, which finally brought a good clinical and biological response. In April 1996, CSA was withdrawn because of uncontrolled hypertension and rising creatinine, and was replaced by AZA (150 mg/day).

Two months later, as prednisone was at $\mathbf{1 7 . 5}$ $\mathrm{mg} /$ day, the disease flared up (CK $5550 \mathrm{U} / \mathrm{l}$ ). As MTX was increased to $25 \mathrm{mg} /$ week, liver enzymes (AST and ALT) rose again. A liver biopsy showed periportal fibrosis compatible with toxicity of MTX, which was then stopped. AZA was increased to $250 \mathrm{mg} /$ day and prednisone to $60 \mathrm{mg} /$ day. In May 1998, as prednisone had been tapered to $30-20 \mathrm{mg}$ on alternate days, $\gamma$-glutamyltransferase and alkaline phosphatase rose. A second liver biopsy disclosed new alterations affecting mainly biliary vessels, with periportal inflammation and Ito's cells hyperplasia, compatible with AZA toxicity. After its withdrawal, liver enzymes returned to normal, but a new flare occurred four weeks later (CK $2618 \mathrm{U} / \mathrm{l}$ ).

While keeping prednisone at $30-20 \mathrm{mg}$ on alternate days, monthly high dose IV immunoglobulins were added at $0.4 \mathrm{~g} / \mathrm{kg} / \mathrm{day}$ for five days, which induced a good and quick response (fig 1). At the end of the first course, CK was back to normal, and pain, which was present when any movement was made, decreased sufficiently to allow the patient to climb four flights of stairs without symptoms. The patient acknowledged a $90 \%$ pain improvement (from 10 to 1 on a $0-10$ pain scale), and had no 


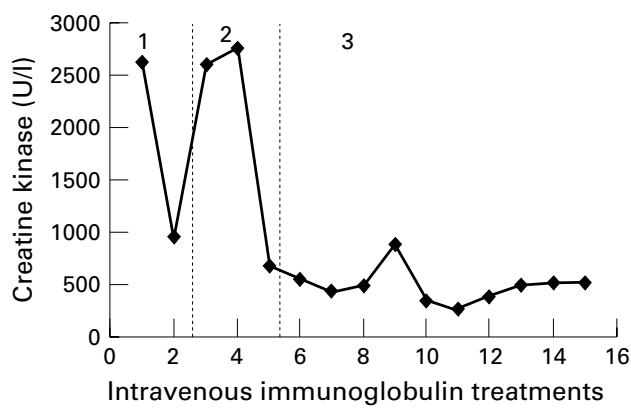

Figure 1 Creatine kinase (CK) evolution during 15 successive monthly intravenous immunoglobulin treatments given according to three different regimens: (1) 0.4 $\mathrm{g} / \mathrm{kg} /$ day for five days; (2) $0.8 \mathrm{~g} / \mathrm{kg} /$ day for two days; (3) $0.8 \mathrm{~g} / \mathrm{kg} /$ day for one day only.

tiredness, weakness, or pain on exertion. Moderate symptoms, correlating with increased CK (959 U/1), reappeared before the second course, but quickly disappeared after the next treatment.

Although intervals between courses were shortened by five days, the next couple of months were characterised by increasing symptoms the week before treatment. To decrease length of stay in hospital, IV immunoglobulins were then given over two days $(0.8 \mathrm{~g} / \mathrm{kg} /$ day $)$ every four weeks (fig 1). Symptoms resolved completely ( 0 on the $0-10$ pain scale), and after two months IV immunoglobulins were further decreased to $0.8 \mathrm{mg} / \mathrm{kg} /$ day for one day only (fig 1). No major clinical or biological change was noticed over the courses (pain never exceeded 1 on the $0-10$ pain scale). In July 1999 the patient started to have mechanical hip pain. Investigations disclosed bilateral osteonecrosis, which pushed us to decrease prednisone further (up to then, kept at 30-20 mg on alternate days since the beginning of IV immunoglobulin treatment). At the beginning of 2000 , slow progressive steroid reduction is continuing, and the myositis is well under control with $0.8 \mathrm{~g} / \mathrm{kg} /$ day monthly IV immunoglobulins, prednisone now at $25-10 \mathrm{mg} /$ day on alternate days (its lowest dose ever), and no immunosuppressive agents.

\section{Discussion}

Numerous mechanisms of action have been proposed to explain the benefits of high doses of IV immunoglobulins in various and heterogeneous autoimmune diseases, based on in vitro and animal studies. The older hypotheses, based on the idiotypic-anti-idiotypic network with neutralisation of pathogenic autoantibodies, were never confirmed or invalidated. Other hypotheses have since been proposed: those more relevant for PM, because of the putative central role of $\mathrm{T}$ cells, might be blockade of $\mathrm{Fc}$ receptors on phagocytic cells, inhibiting antibody dependent, cell mediated cytotoxicity, with modulation of the $\mathrm{T}$ cell function and antigenic recognition. Suppression of cytokines such as tumour necrosis factor or interleukin 1 might also be involved. Other mechanisms, such as inhibition of membranolytic attack complex formation or effects on superantigens, are less likely to be significant in PM but might be relevant in other diseases, including $\mathrm{DM} .{ }^{5} \mathrm{~A}$ recently discovered IgG receptor $(\mathrm{FcRn})$, located mainly in endothelial endosomes, ${ }^{6}$ has been proposed to prevent degradation of phagocytosed IgGs in lysosomes, allowing their return to the blood, where they can perpetuate their potentially pathogenic role. IV immunoglobulins could saturate those receptors, increasing IgG degradation in proportion to their total plasmatic concentration.

The standard IV immunoglobulin dose used to treat PM/DM is $2 \mathrm{~g} / \mathrm{kg}$ monthly (given over two or five days depending on authors). As lower doses have been proved to be efficient in autoimmune thrombopenic purpura, ${ }^{7}$ we decided to test a lower dose after a few months of the standard regimen in our patient. Doses were reduced to less than half $(0.8 \mathrm{~g} / \mathrm{kg})$ monthly, requiring only one day's stay in hospital. The immediate clinical response was excellent and has been sustained over the one year follow up.

Although IV immunoglobulins are costly, their use for the treatment of autoimmune diseases is rapidly expanding, without good doseresponse studies to rely on. Furthermore, for some patients no satisfactory alternative exists, and the treatment has to be given over a prolonged period of time. Dose reduction for maintenance treatment, reducing the time spent in hospital, is an alternative that could certainly reduce costs and, possibly, side effects. The efficacy of the lower maintenance dose of IV immunoglobulin treatment, as suggested by this case of PM, should be further confirmed by controlled trials before its general introduction.

1 Dalakas MC, Illa I, Dambrosia JM, Soueidan SA, Stein DP, Otero C, et al. A controlled trial of high-dose intravenous immune globulin infusions as treatment for dermatomyositis [see comments]. N Engl J Med 1993;329:1993-2000.

2 Cherin P, Herson S, Wechsler B, Piette JC, Bletry O, Coutellier A, et al. Efficacy of intravenous gammaglobulin therapy in chronic refractory polymyositis and dermatomyositis: an open study with 20 adult patients [see comments]. Am J Med 1991;91:162-8.

3 Mastaglia FL, Phillips BA, Zilko PJ. Immunoglobulin therapy in inflammatory myopathies. J Neurol Neurosurg Psychiatry 1998;65:107-10.

4 Zini JM, Tobelem G. Immunoglobulins in hematology. Immunologic thrombopenic purpura. Ann Med Interne (Paris) 1993;144:514-17.

5 Dalakas MC. Mechanism of action of intravenous immunoglobulin and therapeutic considerations in the treatment of autoimmune neurologic diseases. Neurology 1998; 51(suppl 5):S2-8.

$6 \mathrm{Yu} \mathrm{Z,} \mathrm{Lennon} \mathrm{VA.} \mathrm{Mechanism} \mathrm{of} \mathrm{intravenous} \mathrm{immune}$ Yu Z, Lennon VA. Mechanism of intravenous
globulin therapy. N Engl J Med 1999;340:227-8.

7 Mori PG, Lanza T, Mancuso G, De Mattia D, Catera P, Miano C, et al. Treatment of acute idiopathic thrombocytopenic purpura (AITP): cooperative Italian study group results. Pediatr Hematol Oncol 1988;5:169-78. 